\title{
LA AUTONOMÍA JUDICIAL DE LOS JUDÍOS DE ZARAGOZA: LA NORMATIVA DE $1376^{*}$
}

\author{
ASUNCIÓN BLASCO MARTÍNEZ \\ Universidad de Zaragoza
}

\section{ESTADO DE LA CUESTIÓN}

El sistema judicial seguido en la aljama de los judíos de Zaragoza durante el siglo XIV fue estudiado por Hershman en 1943 '. Su trabajo, basado en los Responsa de rabí Iş̧aq bar Š́šet Perfet que fue rabino de la comunidad zaragozana entre los años 1372 y $1386^{2}$, constituye un punto de partida obligatorio para estudiar las instituciones judiciales aragonesas en la segunda mitad del siglo. Casi simultáneamente se daba a conocer el excelente trabajo de Neuman ${ }^{3}$ realizado sobre los Responsa de unos cuantos rabinos ilustres. Las fuentes utilizadas en ambos casos proporcionan una información valiosísima sobre los tribunales judíos, su legislación y competencias. Pero estas dos obras, esenciales para iniciarse en el tema, resultan insuficientes y a veces algo confusas para llegar a conocer el grado de autonomía judicial de los judíos de Zaragoza durante la Baja Edad Media.

Cabe destacar que aunque tanto Serrano como Baer abordaron la cuestión judicial 4, fue Lacave quien, en su excelente estudio sobre un pleito por una herencia, proporcionó datos inéditos de gran interés acerca del procedimiento civil seguido en la aljama zaragozana en

- En la realización de este trabajo me he beneficiado parcialmente de la ayuda del Proyecto $n^{2}$ PB87-0011-C02-02 de la Dirección General de Investigación Científica y Técnica (DGICYT) del Ministerio de Educación y Ciencia.

1 A. M. Hershman, Rabbi Isaac ben Sheshet Perfet and His Times, New York 1943.

2 A esa época corresponden sus Responsa nos 152-187 y 382-518.

${ }^{3}$ A. A. Neuman, The Jews in Spain. Their Social, Political and Cultural Life during the Middle Ages, Philadelphia 1942, 2 vols.

4 M. Serrano y Sanz, Orlgenes de la dominación espatiola en América. T. I: Los amigos y protectores aragoneses de Cristobal Colón, Madrid 1918, pág. XXII, y Y. [Fritz] BAER, Historia de los judios en la España cristiana (Traducción castellana por J. L. Lacave), Madrid 1981, I, págs. 121, 186-188 y 355-360; II, págs. 655-663. 
1465 5. Por lo que a mí respecta, en anteriores artículos me he ocupado del procedimiento penal vigente en esa comunidad, a raíz de un caso de adulterio allí registrado en $13688^{\circ}$.

Las líneas generales del presente trabajo se hallaban esbozadas en la bibliografia, pues ya se sabía que los judíos de Zaragoza gozaban de cierta autonomía judicial, sancionada por el soberano, patente en un tribunal ordinario (en hebreo, bêt-dinn), que juzgaba las cuestiones civiles, en un tribunal especial que se ocupaba del juicio de los malsines, y en un juez de apelaciones propio ? Pero quedaban abiertos numerosos interrogantes: ¿cómo fueron adquiriendo los judíos zaragozanos estas prerrogativas? ¿alcanzaron un corpus juris propio? ¿cuándo se institucionalizó la figura del juez de apelaciones en Zaragoza? ¿de qué manera se solventaban los litigios entre personas de religiones diferentes?

Para responder a todas estas cuestiones, se imponía la necesidad de buscar en la documentación real y notarial nuevos datos que permitieran delimitar el grado de independencia judicial alcanzado por la comunidad judía de Zaragoza, casi siempre en pugna con el rey -era su principal protector y también su más temible enemigo-, con los oficiales reales - trataron de incluir a los judíos en su ámbito jurisdiccional para obtener los ingresos económicos que ello les reportaba- e incluso con la Iglesia, que no regateó esfuerzos en su afán, casi siempre fallido, de hacer extensiva su jurisdicción a los judíos ${ }^{8}$.

1. El ESTATUTO VIGENTE hASTA 1376: LA CONQUISTA DE LA JURISDICCIÓN PENAL

En los siglos XIV-XV casi todos los judíos aragoneses poseían tribunales propios para administrar justicia de acuerdo con la ley judía. Pero esta autonomía no era absoluta ni idéntica para todas

3 J. L. LACAVE, «Pleito judío por una herencia en aragonés y caracteres hebreos», Sefarad XXX (1970) 325-338; y XXXI (1971) 49-102.

6 A. BlasCo, «Avance de estudio de un caso de adulterio en la aljama de Zaragoza (siglo XIV)", Ninth World Congress of Jewish Studies (Jerusalem 1986), págs. 105-112; IDEM, "El adulterio de doña Lumbre, judía de Zaragoza. Causas y consecuencias", Michael XI (1989) 99-120.

7 A. Hershman, Rabbi Isaac, págs. 99-100 y 120-122.

${ }^{8}$ La Iglesia trató de impugnar los matrimonios, bastante frecuentes, entre judíos consanguíneos (Archivo de la Corona de Aragón [= ACA], Reg. 2207, fol. 5v.) y de poner al pueblo hebreo bajo la Inquisición medieval (A. BLASCO, "La Inquisición y los judíos en Aragón en la segunda mitad del siglo XIV», Aragón en la Edad Media VII [1987] 81-96). 
las aljamas del reino, sino que en cada caso dependía de la voluntad del monarca que era su juez supremo ${ }^{9}$. Sólo el rey podía facultar a una comunidad para juzgar cuestiones civiles o criminales e incluso para imponer la pena de muerte, en contra de lo dispuesto por la ley judía, que únicamente permitía el ejercicio de la jurisdicción penal al Sanedrín.

El soberano controlaba la independencia judicial de sus aljamas mediante provisiones y privilegios particulares que adquirían la efectividad de una ley ${ }^{10}$. Generalmente, y salvo contadas excepciones, los reyes confirmaron las concesiones otorgadas por sus predecesores $y$, de esta manera, se fue constituyendo la normativa judicial de cada una de las aljamas del reino.

Retrocediendo en el tiempo, me consta que en 1239 la aljama de Zaragoza recibía autorización real para designar sus propios jueces. Ellos debían juzgar tanto los pleitos suscitados entre judíos como los promovidos entre judío y cristiano a instancias de éste. Los oficiales cristianos se encargarían de ejecutar la sentencia y, sólo en caso de homicidio, de percibir la multa correspondiente. Así figuraba en los fueros, y así fue confirmado en 1247, 1299, 1304, 1376 y $1378 " ~ "$

Hasta el año 1271 los judíos de Zaragoza solamente tuvieron un juez judío para dilucidar sus conflictos internos. Fue precisamente en ese año, a raíz de la ascensión de unos cuantos personajes de la aljama a determinados puestos de responsabilidad política y económica, cuando la comunidad consiguió del rey Jaime I la ratificación de una ordenanza promulgada por Jahudán de la Caballería, en virtud de la cual tres de sus miembros, libremente elegidos por ella, debían juzgar las cuestiones estrictamente judías. En caso de desacuerdo, se podría apelar a Salomón Alfaquí, elevado a la categoría de juez supremo ${ }^{12}$.

El 11 de abril de 1280 Pedro el Grande ratificaba dicho privilegio al tiempo que comisionaba a veinticinco miembros del consejo de la

\footnotetext{
9 Por ejemplo, en Cataluña no existía la figura del juez de apelaciones tan típica de Aragón; las funciones que el merino de Zaragoza ejercía respecto de los judíos se corresponden con las que desempeñaba el baile en Cataluna, Valencia, Mallorca, etc.

$10 \mathrm{~J}$. RÉGNE, History of the Jews in Aragon. Regesta and Documents 1213-1327, (ed. Y. T. Assis), Jerusalem 1978, $\mathrm{n}^{\circ} 458$, y F. BAER, Die Juden im christlichen Spanien. Urkunden und Regesten, vol. I: Aragonien und Navarra, Berlin 1929, nol 91 y 118.

$"$ F. BAER, Die Juden, n 91 (1); J. REgne, History, n²720, y ACA, Reg. 1684, fols. 101-103.

12 J. REgné, History, nos 458, 461, y F. BAER, Die Juden, n² 104.
} 
aljama para que, junto con la mayor parte de ella, procedieran a la elección de las personas que ejercerían el cargo de juez durante un lustro ${ }^{13}$. Los elegidos se hallaban revestidos de atribuciones suficientes para detener, apresar o desterrar al culpable, según se venía haciendo en otras aljamas judías aragonesas y catalanas por esos mismos años ${ }^{14}$. Se permitía recurrir ante el rey contra la sentencia de los mencionados magistrados ${ }^{15}$, pero la cuestión de la apelación en las causas seguidas entre judíos todavía no estaba suficientemente clara ${ }^{16}$.

En 1285, debido a la falta de acuerdo existente entre los propios judíos al aplicar la ley - fiel reflejo de la división social registrada en esa época en la aljama zaragozana por cuestiones tributarias " Pedro el Grande encomendaba la reglamentación procesal de la comunidad a los jueces judíos ${ }^{18}$, al tiempo que se reafirmaba en su postura de reforzar su jurisdicción ${ }^{19}$ : así lo hacía saber al justicia de Aragón en una carta dada en Barcelona a 18 de julio de 1285 y así lo comunicaba siete años después al merino de Zaragoza ${ }^{20}$. Finalmente, fueron los adelantados - no los jueces- quienes elaboraron la normativa a seguir en la elección de los magistrados judíos, hecho que originó la protesta de un sector de la sociedad muy sensibilizado ante la preponderancia que el organismo ejecutivo

13 J. REgnt, History, ne 776, y F. BAER, Die Juden, n 118. Dicho privilegio fue confirmado el 22 de febrero de 1368 por Pedro el Ceremonioso. ACA, Reg. 917, fols. 16-17.

${ }^{14}$ Por lo que se refiere a Aragón, véase J. Régné, History, n 942. Para Cataluña, ibid., n² 823, y F. BAER, Die Juden, n 121.

is J. REGá, History, no 947 y 2217.

16 A raíz del conflicto suscitado entre los Bilforat y los Abenbruch, de Zaragoza, el 3.XI.1284 Pedro el Grande encomendó al justicia Juan Gil Tarín la tarea de averiguar si la apelación estaba contemplada en el procedimiento hebraico, porque los Abenbruch afirmaban que «inter judeum et judeum non potest nec debet iuxta zunam ebraicam appellari» F. BAER, Die Juden, pág. 140.

17 Véase J. RéGne, History, $\mathrm{n}^{\circ}$ XVI, F. BAER, Die Juden, $\mathrm{n}^{\circ} 129$, y Y. T. Assis, "Los judíos de la Corona de Aragón y sus dominios", en H. BeINART (ed.), El legado de Sefarad, Jerusalem 1992, págs. 87-88.

18 J. REgne, History, nos 776 y 1347, y F. BAER, Dei Juden, n 118.

19 Con motivo de un pleito todavía pendiente entre judíos de Zaragoza, el rey recuerda al justicia de Aragón que las causas entre judios deben ser resueltas de acuerdo con la zuna judaica y por jueces judíos. J. REGNE, History, n 1347.

20 En A. Canellas LóPez, Colección Diplomática del Concejo de Zaragoza (12761285), II, Zaragoza 1975, $\mathrm{n}^{\circledR} 415$, y J. REGNÉ, History, $\mathrm{n}^{\circ} 2649$. 
estaba adquiriendo. La intervención del merino, por orden del Rey, no se hizo esperar ${ }^{21}$.

En 1299 Jaime II procedía a confirmar el privilegio que su abuelo Jaime I había otorgado a la aljama de Zaragoza ${ }^{22}$, y doce años después el propio don Jaime daba un paso más en el afianzamiento de la jurisdicción de los judíos, al designar juez de apelaciones de todos los judíos del reino de Aragón a Bahiel Constantiní, vecino de esa ciudad. Treinta años más tarde este nombramiento era ratificado por su sucesor Alfonso el Benigno ${ }^{23}$, pero al parecer el cargo se extinguió cuando murió la persona que lo desempeñaba. Los judíos zaragozanos siguieron presentando sus recursos contra la sentencia del tribunal judío ante el rey, y éste, según el caso, encomendaba la resolución del litigio al canciller ${ }^{24}$, al merino ${ }^{25}$, etc.

Pedro el Ceremonioso confirmó y delimitó los derechos semilegales que algunas aljamas se habían arrogado basándose en una antigua tradición ${ }^{26}$. Durante su reinado, los municipios cristianos consiguieron plenas atribuciones para juzgar las causas penales, iniciativa que fue emulada por los judíos de Zaragoza, que en 1346 conseguían un privilegio real -es idéntico a los otorgados previamente a los judíos de Barcelona (1342) y Teruel (1343) ${ }^{27}$ - por el que los adelantados, junto con otros cinco judíos de la comunidad libremente elegidos por ellos, quedaban facultados para fallar los delitos de malsindad y para aplicar a los culpables la pena capital. $\mathrm{Su}$ veredicto, que era irrecusable, sería ejecutado por los oficiales cristianos ${ }^{28}$. Esta concesión ampliaba considerablemente la jurisdic-

\footnotetext{
21 J. REGNE, History, n² 2587.

22 J. REGNE, History, n²720, y F. BAER, Die Juden, n² 142.

${ }^{23}$ F. BAER, Die Juden, págs. 151-152.

24 Por ej., ACA, Reg. 428, fols. 250v-251 y 267v y Reg. 431, fols. 224v-225.

25 Así, en ACA, Reg. 431, fol. 242v, y Reg. 432, fol. 11v.

26 Y. BAER, Historia, I, pág. 355.

${ }^{27}$ Para Barcelona, A. Pons: Los judios del reino de Mallorca durante los siglos XIII y XIV, Palma de Mallorca 1984, II, págs. 292-293. Por lo que se refiere a Teruel, ACA, Reg. 874, fol. 53.

${ }^{28}$ ACA, Reg. 879, fol. 103. Hay copia de 1384 inserta en carta de traslado en ACA, Reg. 1687, fols. 234v-238. F. BofARULL publicó una copia de este mismo privilegio del año 1390 en "Los judíos malsines», Bolettn de la Real Academia de Buenas Letras de Barcelona VI (1911-1912) 209-210. Del juicio de los malsines me ocupo en otro trabajo todavía inédito.
} 
ción criminal de los judíos de Zaragoza frente a la política centralista ejercida desde la corona.

Por esos mismos años los miembros de la aljama de Zaragoza podían presentar 'sus recursos ante el merino de la ciudad a quien competía

"cognoscendi de quibuscumque causis et questionibus existentibus inter sarracenum et sarracenum ac judeum et judeum et inter christianos agentes et judeos ac sarracenos defendentes»

pues así lo había ordenado en 1346 Pedro el Ceremonioso ${ }^{29}$ y así lo confirmaría este soberano en 1347,1358 y $1365^{30}$. Y de este mismo modo sucedía en la realidad, pues me consta que el 23 de abril de 1354 Açach Mazal, judío de Zaragoza, retiraba la denuncia que previamente él mismo había presentado ante la corte de Juan Ximénez de Osca, merino de la ciudad, contra Jucé Ripol ${ }^{31}$, y veinte años después (en 1375) Durona, esposa de Açach Abenaçora y habitante en Zaragoza, acudía a Blasco de Azlor, en aquel tiempo merino de la ciudad, en demanda de justicia, pues su marido había incumplido el contrato matrimonial que años antes ambos habían suscrito ${ }^{32}$.

A lo largo de todos estos años el monarca dio pruebas de su decidida voluntad para que se aplicara la ley judía en todas las causas suscitadas entre judíos ${ }^{33}$. En la década de los años 60 la ingerencia judicial de las autoridades cristianas en asuntos judíos debió de ser abusiva e incluso intolerable, según se desprende de las protestas formuladas al respecto en 1362 por los dirigentes de la aljama zaragozana ${ }^{34}$.

En 1368 Pedro el Ceremonioso, a ruegos de los judíos de Zaragoza, confirmaba la legislación que en 1280 Pedro el Grande había otorgado a todas las comunip̧ades judías del reino de Aragón, por

${ }^{29}$ Se inserta la noticia en ACA, Reg. 1206, fol. 92.

${ }^{30}$ Respectivamente, en ACA, Reg. 1206, fol. 92, Reg. 966, fol. 85 y Reg. 1206, fols. 92-92v.

31 Archivo Histórico de Protocolos de Zaragoza [= AHPZ], Pedro Martínez de Casenat, 1354, fol. 8v.

32 AHPZ, Blasco Aznárez de Ansó, 1375, fols. 43v-47. Publicado parcialmente por M. Serrano y Sanz, Origenes, pág. CCCCLI, Ap. I.

${ }^{33}$ ACA, Reg. 1186, fol. 55v (1359.II.18) y Reg. 1180, fol. 186v (1362.XII.2).

${ }^{34}$ ACA, Reg. 1180, fol. 187v. 
la que correspondía a los magistrados judíos — su número podía oscilar entre dos y siete- entender en las causas promovidas entre judíos y en aquellas suscitadas entre cristiano y judío en el caso de que el demandante fuese cristiano. Estos jueces debían juzgar y castigar de acuerdo con el derecho hebreo a todos sus correligionarios que, de alguna manera, hubiesen atentado contra la ley de Moisés. También estaban capacitados para elaborar «statuta et prohibitiones" y para imponer pena de "vetita et alatma et niduy". Sin embargo, la aplicación de las sanciones competía al baile y, en el caso de Zaragoza, al merino ${ }^{35}$. Dos años después, el Ceremonioso concedía a los judíos zaragozanos un privilegio por el que ningún oficial cristiano, ordinario o extraordinario, podía proceder por vía de inquisición contra la aljama, sus adelantados, jueces, oficiales u otros miembros. Además, el monarca diferenciaba entre las causas, cuestiones y pleitos, tanto civiles como criminales, promovidos entre cristianos, de un lado, y la aljama o alguno de sus contribuyentes, de otro, que debían ser resueltos por las autoridades judiciales cristianas según fuero, usos y costumbres del Reino, y los litigios suscitados entre judíos, que debían solventarse de acuerdo con la ley, el derecho hebreo y los estatutos de la aljama. Esta concesión fue ratificada en 1373 por el propio Rey ${ }^{36}$.

\section{El REGLAMENTO DE 1376}

En vísperas de la implantación de la nueva normativa judicial, el único juez cristiano autorizado por el rey para juzgar y castigar tanto los litigios mixtos como

«quibuscumque causis criminalibus motis et movendis inter judeum et judeam et sarracenum et sarracenam»

seguía siendo el merino ${ }^{37}$. Desde que en 1372 se hiciera cargo de la

${ }^{35}$ ACA, Reg. 917, fols. 16-17 y Reg. 918, fols. 105-105v.

36 ACA, Reg. 924, fols. 47-47v y 57-58v. La confirmación de 1373 se encuentra también inserta en carta de traslado del 1408 XI 28, en ACA, Reg. 2206, fol. 93v.

${ }^{37}$ Así se indica en una carta de agosto de 1373 enviada por el rey a Blasco Aznárez de Azlor, merino de Zaragoza, que se conserva en AHPZ, Blasco Aznárez de Ansó, 1375, fols. 43v-47. 
dirección espiritual de sus miembros rabí Ișhaq bar Śéset -encabezaba una corriente de opinión partidaria de potenciar la autonomía judicial de la comunidad- se percibe en la aljama de Zaragoza un interés por los asuntos judiciales hasta entonces desacostumbrado. Fruto de este tira y afloja entre el rey y los judíos fue la ordenación sancionada en 6 de agosto de 1376 por Pedro el Ceremonioso, que establecía un nuevo sistema judicial para esa aljama.

El citado reglamento, que ha llegado hasta nosotros gracias a una copia notarial de 1380 y a otra reproducción inserta en carta de traslado, en un registro de cancillería de $1382{ }^{38}$, suponía la aceptación, por parte del soberano, de las reivindicaciones sostenidas por la aljama zaragozana y por su rabino Ishaq. De un lado, el monarca sancionaba privilegios anteriores y autorizaba a los judíos de Zaragoza para elegir entre ellos de dos a cinco magistrados que resolvieran las causas entre la comunidad y su colecta con otros judíos foráneos, según el rito y la ley judaica ${ }^{39}$. Pero además -en ello radica la principal novedad-, el soberano les facultaba para elegir un juez especial, judío, que entendiera en las apelaciones presentadas a las sentencias dictadas por los mencionados jueces de acuerdo con la ley judía ${ }^{40}$. De este modo, pretendía evitar a los litigantes judíos las molestias y los costos elevados en los que inevitablemente se veían envueltos al recurrir al merino y a otros tribunales cristianos: en efecto, las cortes judías constituían la vía judicial más rápida y adecuada para las gentes de la judería por utilizar el procedimiento oral, en virtud de diversos privilegios. A fin de garantizar el cumplimiento de las nuevas disposiciones, don Pedro exigía la colaboración

38 La primera copia se inserta en carta de traslado dada en Zaragoza a 1380.II.6 (AHPZ, Domingo Pelagut). La otra está en ACA, Reg. 1273, fols. 45-47v (Barcelona, 1382.IX.4). Por la falta de espacio no se ha podido incluir el documento, que será publicado en otro lugar.

${ }^{39}$ «Ut ... eligantur ... de duobus in quinque iudeis qui, ut iudices dicte aliame et ipsorum, audiant questiones, lites, controversias et causas que quomodolibet moveri posent et posunt ad invicem inter singulares ipsius aliame et sue contributionis ac collecte, masculini sexus seu femenini vel inter aliquem seu aliquos de ipsis, ex una parte, et alium seu alios iudeos extrannios, ex altera, easque lites ... deçidant fine debito et determinent iuxta ritum iudeorum et ebraycam legem». Véanse los documentos citados en la nota 38.

40 «Eligatur quoque, ex ipsis, qui appellationes emergentes et emittendas ex iudiciis et sentenciis ferendis per dictos iudeos eo modo audiat et eas ac ipsarum qualibet decidat et determinet iuxta ritum et ebraycam legem...». Véanse los documentos citados en la nota 38 y F. BAER, Historia de los judios en la Corona de Aragón (s. XIII y XIV) (trad. A. Sanmartín Rivera), Zaragoza 1984, pág. 119. 
de los dirigentes de la aljama y de las autoridades judiciales cristianas. Por una parte, comisionaba a los adelantados para que, en lo sucesivo, hicieran públicos los mencionados estatutos, dentro de los ocho días siguientes a su nombramiento ${ }^{41}$, y para que velaran por su observancia, de suerte que ningún miembro de la aljama volviera a presentar sus demandas y recursos ante los tribunales cristianos so pena de incurrir en multa de mil maravedíes de oro; pero, además, el soberano ordenaba al merino de Zaragoza y a los otros funcionarios reales que se abstuvieran de intervenir en los litigios estrictamente judíos, remitiéndolos a los jueces de la aljama. Y con el fin de disipar cualquier reticencia por parte de los judíos, el monarca mandaba expresamente al gobernador y al justicia de Aragón que obligaran a los funcionarios reales a desistir de cualquier intromisión en las cuestiones estrictamente judías ${ }^{42}$. El reglamento de 1376 no hacía referencia alguna a la jurisdicción criminal ni al juicio de los malsines, hecho que no es de extrañar si, como he apuntado anteriormente y como a continuación intento demostrar, el rabino Işaq bar Šéset colaboró en la redacción de dicha normativa.

Las razones que me inducen a pensar que Ribaš pudo haber participado en la elaboración del estatuto de 1376 son las siguientes:

- El mencionado reglamento representa un avance jurisdiccional importante para la aljama de Zaragoza, sobre todo por lo que se refiere a la institucionalización del tribunal de apelaciones local ${ }^{43}$, y es de todos conocido que a rabí Isshaq bar Šéset le repugnaba la idea de poner a un judío en manos de los jueces gentiles, especialmente si se trataba de juzgar un delito contra los preceptos religiosos de la Torá, pues según él decía:

"para precipitar el asalto contra los judíos una conversación ociosa de los jueces del país vale más que toda nuestra Torá"

y añadía:

«en toda orden de las autoridades a un judío, aunque se trațe de una simple multa pecuniaria, hay pena de muerte ${ }^{44} m$.

${ }^{41}$ Así procedieron en 1380 los nuevos adelantados de la aljama. AHPZ, Domingo Pelagut, 1380.II.6.

42 AHPZ, Domingo Pelagut, 1380.II.6.

${ }^{43}$ La existencia del citado tribunal se ha documentado también en otros puntos de Aragón. Véase A. Hershman, Rabbi Isaac, pág. 121.

4 Y. BAER, Historia, I, pág. 368. 
Por lo que bien pudo ser Ribaš el inspirador de esta cláusula.

- El estatuto era exclusivo para la aljama de Zaragoza, lo cual coincide con las ideas localistas del rabino Ișhaq bar Šéšet expuestas en sus Responsa ${ }^{45}$.

- Por su cargo y de acuerdo con su mentalidad, es lógico que Isshaq bar Šéšet interviniera en todos los asuntos importantes relacionados con la aljama ${ }^{46}$.

- El hecho de que en el reglamento no se aluda a las causas de carácter criminal -me refiero a los delitos de malsindad-, resulta altamente significativo pues rabí Işhaq, que en teoría no se oponía a que los judíos aplicaran la pena de muerte, se mostró siempre muy cauto cuando tuvo que emitir un juicio sobre dichas materias. Así se infiere de una carta suya, dirigida desde Zaragoza a rabí Měnahem he-Aroj, en la que se pronunciaba en los siguientes términos:

"Ya sabes que todo lo que se refiere a las leyes penales no debemos juzgarlo en este tiempo, pues ya han sido abolidas las leyes penales de la Torá ... pues ya sabes que en este país no acostumbramos a juzgar los casos penales y tampoco a cortar manos o pies, ya que esa potestad judicial pertenece al rey".

Idéntica precaución se observa en otra de sus misivas cuando, refiriéndose a los malsines, afirma:

"Si queréis darles muerte ... podéis hacerlo ... y si queréis ser indulgentes ... podéis hacerlo. Y si yo fuera juez con autorización real así lo haría, y no sería indulgente con ellos, a no ser que fuera ésa la voluntad de los parientes del asesinado".

De donde se deduce que en tiempos de rabí Işhaq bar Séšet los judíos aragoneses sólo poseían jurisdicción criminal para juzgar los delitos de malsindad ${ }^{47}$. Por lo tanto, no resulta extraño que en la normativa de 1376 se obviara este asunto, incómodo para Ribaš y sobradamente resuelto por el privilegio de $1346^{48}$.

4s Sobre la teoria de rabí Isbaq acerca de la autonomía de las aljamas, véase su Responsum n² 272; en Y. BAER, Historia, I, pág. 365.

${ }^{46}$ La descripción de la imagen ideal del rabino se recoge en el Responsum $n^{2} 387$ de rabí Isşaq bar Séset; en Y. BAER, Historia, I, pág. 366.

${ }^{47}$ Recoge la noticia Y. BAER, Historia, I, pág. 367.

$48 \mathrm{Al}$ que me he referido anteriormente. Véase la nota 28. 


\section{LAS MODIFICACIONES DE 1382}

El reglamento judicial de 1376 fue sustancialmente modificado el 3 de febrero de 1382, cuando Pedro el Ceremonioso decidió autorizar a los judíos de Zaragoza para que nuevamente pudieran apelar al rey o al merino en el caso de no estar conformes con la sentencia pronunciada por el tribunal ordinario judío. Pero dicha reforma apenas se mantuvo en vigor dos meses, pues el 9 de abril de ese mismo año el propio Rey procedía a su derogación al tiempo que confirmaba la vigencia de la ordenación judicial que él mismo había concedido a la aljama seis años antes ${ }^{49}$. En 1383 el rey Pedro reconocía que los oficiales ordinarios de la aljama eran los únicos que tenían autoridad para intervenir en litigios entre judíos, tanto civiles como criminales, al tiempo que reforzaba y ampliaba la autonomía del tribunal judío encargado de juzgar los delitos de malsindad ${ }^{\text {so. }}$.

\section{LA LEGISLACIÓN JUdicial A FINALES DEL SIGLO XIV}

Al subir al trono Juan I la situación se mantuvo prácticamente igual: el merino no poseía jurisdicción alguna sobre los judíos puesto que éstos no estaban sometidos a los fueros sino a la voluntad del monarca y, en consecuencia, la autoridad del merino de Zaragoza para dirimir litigios entre judíos dependía exclusivamente del poder que en cada caso le confirieran el rey o la reina ${ }^{51}$. El nuevo soberano parecía dispuesto a ampliar la potestad judicial de los judíos, y muy especialmente de la aljama de Zaragoza, que desde 1389 estaba bajo la guía del rabino Hasday Crescas, que gozaba de la confianza del Rey. En efecto, en 1387 el mencionado Hasday recibía del monarca plenos poderes para aplicar a sus correligionarios

\footnotetext{
49 ACA, Reg. 1273, fols. 45-47v.

so Se inserta copia en la confirmación del 23 de marzo de 1384. ACA, Reg. 1.687, fols. $234 \mathrm{v}-238$.

s1 Así lo reconocía Juan I en carta del 23 de febrero de 1387 a los judíos y sarracenos de Zaragoza en la que les recordaba "vos, qui foris et privilegiis regni Aragonum non gaudet nec estis eisdem subiecti sed solam nostram nudam et simplicem voluntatem" (ACA, Reg. 198, fol. 47v.).
} 
la pena de excomunión siempre que lo considerara oportuno, mientras que en 1390 era designado por la reina consorte doña Violante juez único en todo lo referente a los malsines del reino, con plenos poderes paras imponer cualquier pena, incluso la capital ${ }^{52}$. Este nombramiento no suponía la derogación de la legislación anterior, puesto que los adelantados - si asi lo deseaban - podían seguir siendo jueces de los delitos de malsindad, ellos solos o con Hasday.

A comienzos de la década de los 90 , y seguramente como consecuencia del movimiento democrático experimentado en la aljama de Zaragoza por esos años - patente, por ejemplo, en la presencia de artesanos en el tribunal ordinario-, el Soberano favorecía la agilización del procedimiento judicial ante los berorim.

Desde que en 1390 las aljamas zaragozanas (de judíos y mudéjares) pasaron a manos de la reina doña Violante ${ }^{53}$, el merino se hizo cargo tanto de la administración y percepción de las rentas que dicha señora poseía sobre la comunidad judía como del ejercicio de su jurisdicción ${ }^{54}$. Pero el sistema judicial no se resintió del cambio en lo fundamental: en 1393 Juan I confirmaba a la aljama el reglamento de 1376 y cuatro años más tarde la reina viuda doña Violante puntualizaba las cosas un poco más estableciendo que en lo sucesivo los jueces judíos de Zaragoza podrían entender no sólo en las causas promovidas entre judío y judío, judíos y judío o viceversa, sino también en las suscitadas entre la aljama, de un lado, y alguno de sus miembros, de otro "s5. Ese mismo año de 1397, y de nuevo en 1398, el rey Martín ratificaba los privilegios otorgados a la aljama por sus predecesores, al tiempo que ordenaba a sus oficiales cristianos que se abstuvieran de intervenir en los litigios de judíos bajo pena de mil florines ${ }^{56}$.

32 Para 1387, véase F. BAER, Die Juden, n 387 y pág. 607; por lo que se refiere a 1390, ibid. $\mathrm{n}^{2} 396$.

${ }^{53}$ El 19 de junio de 1390 (ACA, Reg. 2027, fols. 123-124). Véase también M.: L. LEDESMA, "El patrimonio real en Aragón a fines del siglo XIV, los dominios y rentas de Violante de Bar", Aragón en la Edad Media II (1979) 135-169, 155.

54 ACA, Reg. 2027, fols. 118 y 120, y Reg. 2031, fol. 55v.

ss Véase, respectivamente, ACA, Reg. 1906, fols. 162-162v. y Reg. 2042, fols. 94v96v.

${ }^{56}$ ACA, Reg. 2189, fols. 100-101. Hay copia en ACA, Reg. 2206, fols. 107v-109 (1409 II 8). 


\section{APLiCACIÓN DE LA NORMATIVA DE 1376 EN EL SIGLO XV}

La normativa judicial de 1376, con ligeras variantes, permaneció vigente a lo largo de casi todo el siglo XV. En 1408 Martín el Humano confirmaba que las causas civiles y criminales de carácter mixto, es decir, entre judíos y cristianos, debían ser juzgadas conforme al fuero, usos, costumbres y libertades del Reino a la vez que ratificaba y ampliaba las prerrogativas concedidas por el Ceremonioso a la jurisdicción judía, pues no sólo reconocía la capacidad de los magistrados judíos para resolver los litigios civiles suscitados entre sus correligionarios, sino que se avenía a no intervenir en los asuntos judíos en busca de beneficios económicos. Poco después, el Soberano autorizaba a los jueces de la aljama de Zaragoza para imponer sanciones, tanto corporales como económicas, y para que uno sólo de ellos pudiese seguir el proceso, tanto en las causas civiles como criminales, hasta la sentencia definitiva o hasta la interlocutoria intermedia ${ }^{57}$.

El 23 de junio de $1415^{38}$, siguiendo las pautas marcadas por la Bula de Benedicto XIII, Fernando I revocó el reglamento judicial de 1376 contemplado en las ordenaciones de la aljama que habían sido aprobadas el 10 de enero de ese mismo año ${ }^{9}$. Cuatro años después el estatuto era restablecido por Alfonso el Magnánimo, que en 1447, en 1448 y de nuevo en 1457 procedía a su ratificación ${ }^{60}$. Su sucesor, Juan II, confirmaba en 1461 el privilegio judicial otorgado a la aljama por Pedro el Ceremonioso y ordenaba que se copiara in extenso el contenido del mismo, pues debido a su antigüedad estaba corroído y apolillado ${ }^{61}$.

Es posible que las decisiones adoptadas en 1476 por las cortes castellanas de Madrigal ${ }^{62}$ contribuyeran a mermar la jurisdicción penal que disfrutaban los judíos aragoneses, y más concretamente

57 ACA, Reg. 2206, fol. 93v (1408.XI.28) y Reg. 2206, fols. 107v-109v (1409.I.16).

${ }^{58}$ M. Serrano y Sanz, Orígenes, págs. CCCClVil-CCCCliX.

59 F. VENDRELL, «Al margen de la organización de la Aljama judaica de Zaragoza», Sefarad XXIV (1964) 81-106, $95 \mathrm{n}^{2}$ XXVIII; fDEM, "En torno a la confirmación real, en Aragón, de la Pragmática de Benedicto XIII", Sefarad XX (1960) 319-351.

60 AHPZ, Jimeno de Alberuela, 1419.III.21. La confirmación de 1447 está en ACA, Reg. 2616, fol. 185; la de 1448 en ACA, Reg. 2616, fols. $268 v$ y 284-285, y la de 1457 en M. Serrano y Sanz, Origenes, pág. CCCCLXXIX.

61 ACA, Reg. 3375, fol. 53 (1461.VII.18).

${ }^{62}$ Y. BAER, Historia, II, pág. 564. 
los zaragozanos. Pero el tribunal ordinario o bêt-din de la aljama zaragozana mantuvo su autonomía en materia civil hasta el momento de la expulsión.

\section{RESUMEN}

La aljama de los judíos de Zaragoza, como otras de Aragón, gozaba de ciertas prerrogativas judiciales controladas por la Corona, en virtud de las cuales los judíos estaban capacitados para dirimir los litigios suscitados entre ellos: existía un tribunal que se ocupaba de las cuestiones civiles (el bêt $-d \imath n$ ), otro especial, que se encargaba de juzgar a los delatores o malsines, y un juez de apelaciones judío designado por la comunidad. En el presente artículo se analiza el desarrollo de esta autonomía a lo largo de los siglos XXIII-XIV y se estudia el reglamento judicial de 1376 de Pedro el Ceremonioso, que en líneas generales se mantuvo vigente hasta el momento de la expulsión.

\section{SUMMARY}

The Jewish aljama of Zaragoza, like some other Jewish aljamas in Aragon, enjoyed certain judiciary privileges, controlled by the Crown, whereby the Jews had the faculty of solving their own quarrels: there was a court for civil causes (the bet $d i n$ ), a special one to judge the informers or "malsines", and a Jewish judge of appeals appointed by the community. This article examines the development of this autonomy during the 13th and 14th centuries, and studies Pedro el Ceremonioso's judiciary regulations of 1376 . This law remained in force, in its broad lines, until their expulsion. 